\title{
Design of Reactive Power Compensation Devices on the Base of Dynamical Simulation of Steelmaking Process
}

\author{
A. Novitskiy ${ }^{1}$, I. Konotop ${ }^{1}$ and D. Westermann ${ }^{1}$ \\ ${ }^{1}$ Department of Power Systems \\ Faculty of Electrical Engineering and Information Technology \\ Ilmenau University of Technology \\ P.O.B. 100565, 98684 Ilmenau (Germany) \\ Phone/Fax number: +0049 (3677) 691490/+0049 (3677) 691496, \\ e-mail: Alexander.Novitzkii@TU-ilmenau.de, Irina.Konotop@TU-Ilmenau.de, \\ Dirk.Westermann@TU-ilmenau.de
}

\begin{abstract}
Alternative current electric arc furnaces (AC-EAF) are characterized by significant active and reactive power consumption. The operation of electric arc furnaces can cause considerable harmonic distortion and voltage fluctuations (flicker) in the electric power system due to the non-linearity of electric arc and stochastic character of arc burning. The distortion level caused by AC EAF operation depends on the stage of the steelmaking process. The novel method of design of reactive power compensation devices on the base of dynamical digital simulation of complete steelmaking process is described in the offered paper.
\end{abstract}

\section{Key words}

Voltage fluctuations, total harmonic distortion, reactive power control, static VAr compensators, power quality.

\section{Introduction}

$\mathrm{AC}$ electric arc furnaces (AC EAF) are characterized by significant power quality impact during the steel-making operation due to the non-linearity of electric arc and stochastic character of arc burning. High power demand of modern arc furnaces necessitates the use of special installations for dynamic reactive power compensation. Electronic equipment of reactive power compensation devices can contribute to the deterioration of power quality in the network. The installation of harmonic filters at the steel plant bus-bar changes the impedancefrequency characteristic of the network and can cause the amplification of interharmonics which are generated due to the arc furnace operation. Under these circumstances it is very important to correctly design the reactive power compensation devices.

Conventional design methods of reactive power compensation devices for steel plants are usually based on the use of simplified deterministic analytic formulas for the estimation of expected harmonic distortion and flicker level at the bus-bar under consideration and harmonic load of filters during the melting process. The dynamic of the power quality impact is usually not considered, or not sufficient considered (for example, the simulation of several seconds of processes for the estimation of voltage fluctuations) [8-15].

The novel method of design of reactive power compensation devices based on dynamical digital simulation of complete steelmaking process is described in the offered paper.

\section{Main Peculiarities of Design Methodology}

\section{A. Power quality considerations for melting process}

The method is based on the digital simulation of steel plant operation taking into account the frequency characteristics of network elements inclusive the impedances of high current circuit of arc furnace and thyristor controlled reactor (TCR) in dependence on the actual firing angle $[1,2]$. These impedances are a part of resonance circuit for harmonics in the steel plant network. Fig. 1 illustrates the correspondence between the simulated voltage spectrum at the steel plant bus and the impedance-frequency characteristic (IFC) of the network. The amplification of interharmonics for the pole frequencies of IFC is clearly seen in the Fig. 1. Instantaneous Volt-Ampere characteristics of the arc are simulated in dependence on the stage of the melting process. Parameters of Volt-Ampere characteristics are changed stochastically in accordance with the simulated statistical distribution. Distribution laws of voltages of arc ignition in dependence on furnace operating stages are based on the investigation [3].

Fig. 2 shows as an example the simulated power consumption for 3 typical operating points of a furnace under study. The characteristics of operating points are depended on melting profiles.

Under the simplified assumption that the melting process can be considered as quasi-stationary state for each 
operating point the expected characteristics of power quality impact of steel plant can be simulated.

Taking into account the durations of furnace operation for each operating point according to the melting profile under consideration and tap-to-tap time the power quality parameters in accordance with international standards or utility requirements can be estimated.

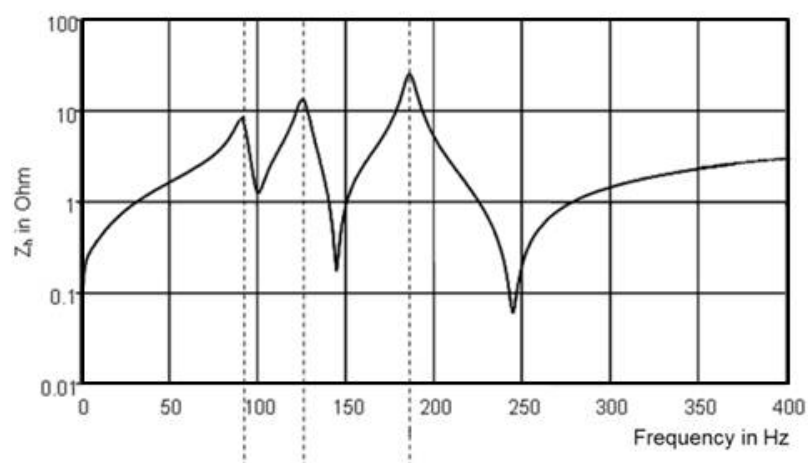

a)

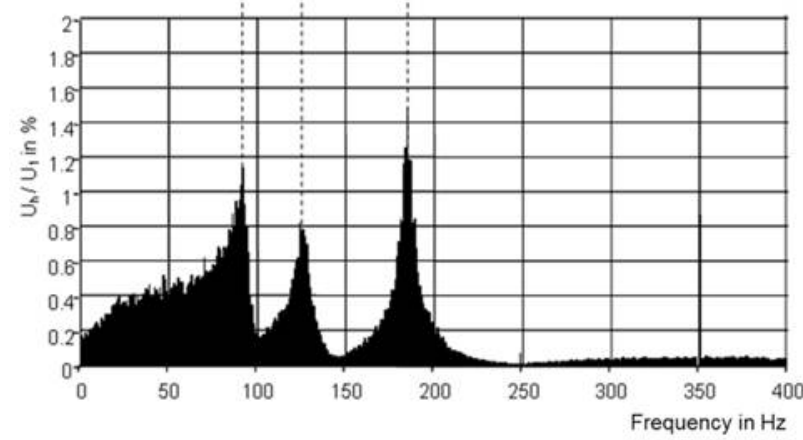

b)

Fig. 1 IFC of the network a) and voltage spectrum b).

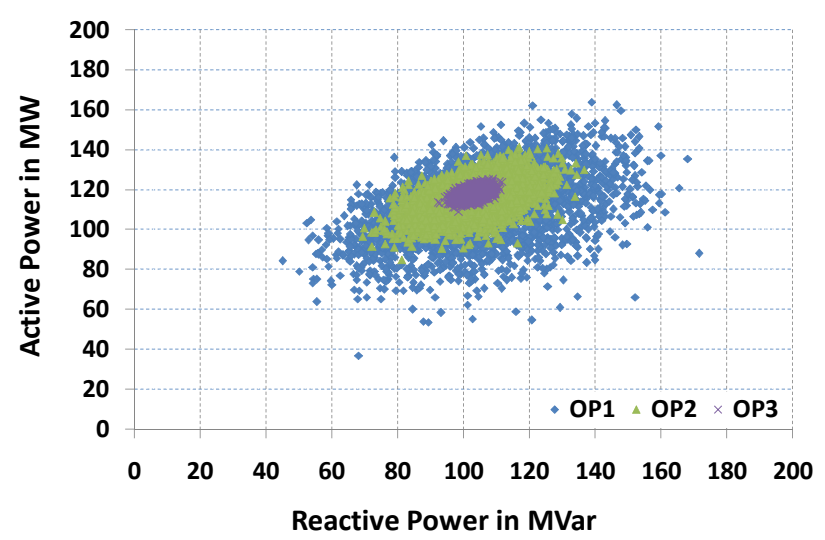

Fig. 2 Power consumption of a furnace simulated for 3 typical operating points (3000 cycles for each OP).

Fig. 3 shows simulated THD time course caused by the simultaneous operation of the furnace with the power consumption presented in the Fig. 3, ladle furnace and TCR at the HV bus-bar of PCC during the steel plant operation. It can be clearly seen from the Fig. 3 that harmonic distortion caused by steel plant operation is depended on the actual operating point of the furnace.

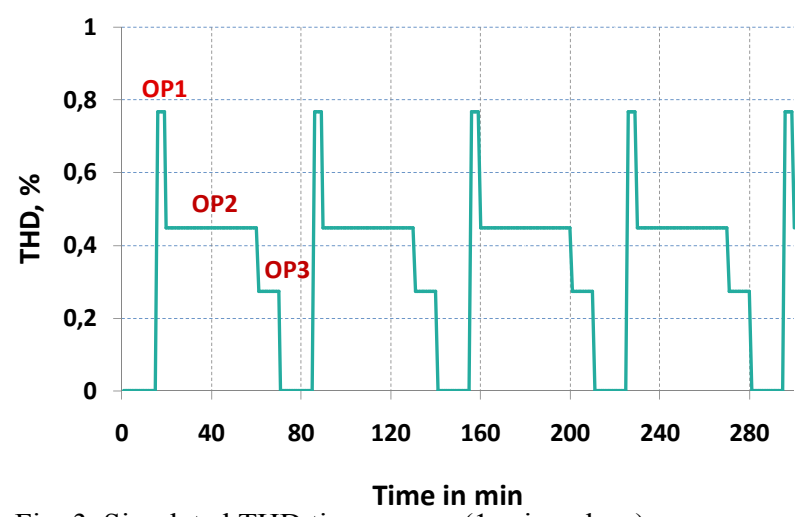

Fig. 3 Simulated THD time course (1-min values)

Calculated time rows of instantaneous voltage values can be easily aggregated in accordance with standard power quality measurement methods [16]. A simplified way of analysis is to form the $10 \mathrm{~min}$ values of power quality quantities from the corresponded $1 \mathrm{~min}$ values. On the base of statistical analysis of computed $10 \mathrm{~min}$ values the quantile of statistical distribution $(95 \%, 99 \%$, etc.) can be easily estimated.

Taking into account the possibility to determine the flicker severity level $\mathrm{P}_{\text {st }}$ from simulated (or measured) flicker values $\mathrm{P}_{\mathrm{st}}(1 \mathrm{~min})$ for time intervals of $1 \mathrm{~min}$ according to equation (1) the estimation of expected flicker levels can be carry out with minimal computing time [3 - 5].

$$
\mathrm{P}_{\mathrm{St}}=\sqrt[3]{\frac{1}{10} \cdot \sum_{\mathrm{i}=1}^{10} \mathrm{P}_{\mathrm{st} \mathrm{i}(1 \mathrm{~min})}^{3}}
$$

Fig. 4 illustrates the determination of the $\mathrm{P}_{\mathrm{st}}$ level based on the $\mathrm{P}_{\mathrm{st}}(1-\mathrm{min})$ values. $\mathrm{P}_{\mathrm{st} \text { (meas.) }}$ - measured values, $\mathrm{P}_{\text {st (calc.) }}-$ values calculated according to (1).

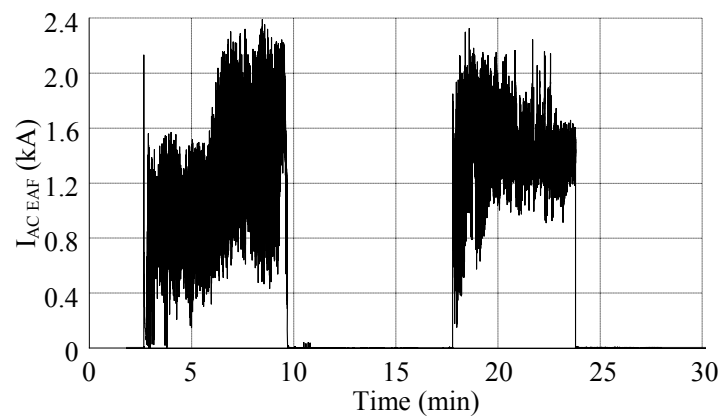

a)

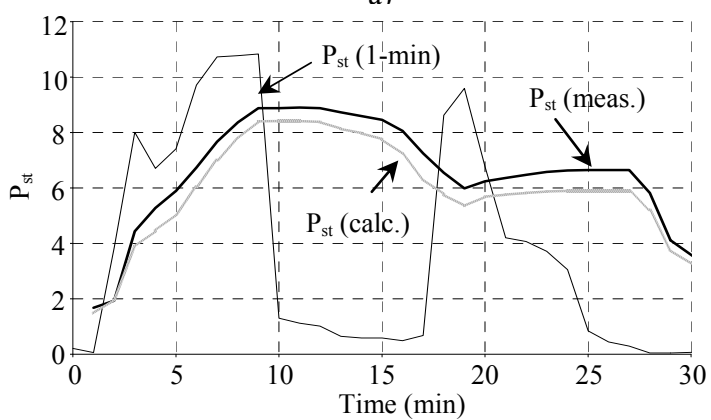

b)

Fig. 4 EAF current a) and flicker values b). 
Fig. 5 shows the simulated flicker values without and with consideration of the influence of TCR reactive power control system. It can be seen from Fig. 5 that due to right choice of the control system parameters the flicker level can be reduced. The TCR control system model developed in [6] was used in the computations presented in Fig. 5.

It must be noted that TCR is a one of main harmonic sources in the steel plant network. In [17] was shown that the contribution of TCR for harmonic distortion at the steel plant bus-bar can be higher than the contribution of the furnace.

\section{B. Inrush transients considerations}

The steelmaking process is accompanied by periodic switching on of non-loaded furnace transformer. The rated power of a modern furnace transformer can be up to 160 MVA. During this process reactive power compensation devices can be significantly stressed by transformer inrush currents and must be designed taking into account possible harmonic impact of inrush currents.

Fig. 6 shows as an example simulated instantaneous values of transformer inrush currents in all three phases. Second harmonic reaches the value over $44 \%$ of the fundamental frequency current and is dominant in the inrush currents presented in the Fig. 6. It must be noted that in some cases the magnitude of inrush current can be many times higher than the magnitude of transformer rated current. It depends on the time point of switching on and the magnetic system of transformer.

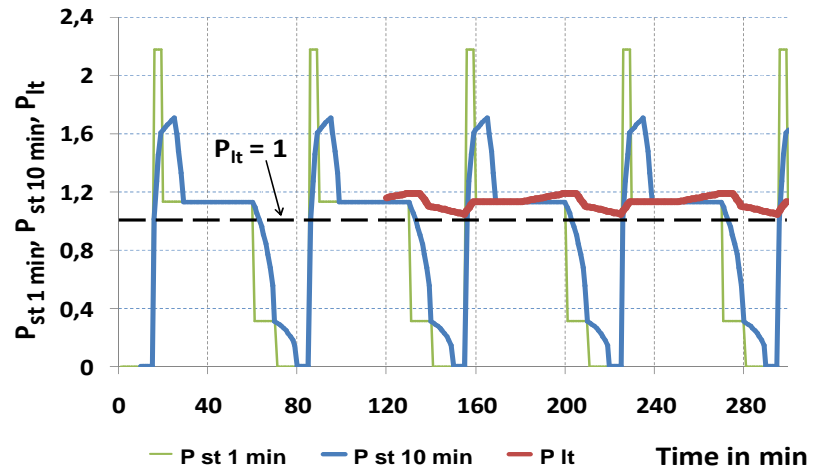

a)

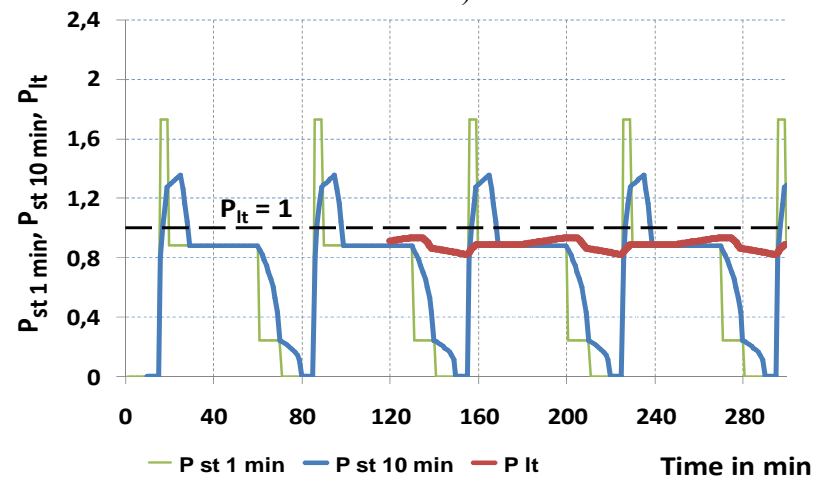

b)
The transformer model considered zero sequence power losses in the nonlinear magnetic system [7] was used for the computations Fig. 6 and 7. Fig. 7 shows harmonic voltages time courses at the steel plant bus-bar during the inrush process.

It must be noted that false designed filters can be destroyed due to the overloading by inrush currents. Such cases are known from international praxis [2].

\section{General recommendations}

Generally all main distortion sources in the steel plant: EAF, LF, TCR and inrush currents of furnace transformer must be considered by the designing of reactive power compensation devices.

Operation conditions of filters in quasi-stationary states of harmonic loading during the melting process and the transient stress caused by transformer inrushes must be estimated.

It must be noted that false parameterization of the control system of TCR can cause the increase of flicker level in the network. Under this aspect the estimation of the efficiency of the TCR control system must be carried out on the stage of the design of reactive power compensation installations.

Information about melting profiles and technology (DRI / scrap, continuous charging, preheating, etc.) is decisive for the correct modeling of steelmaking process and for the estimation of power quality impact of steel plant.

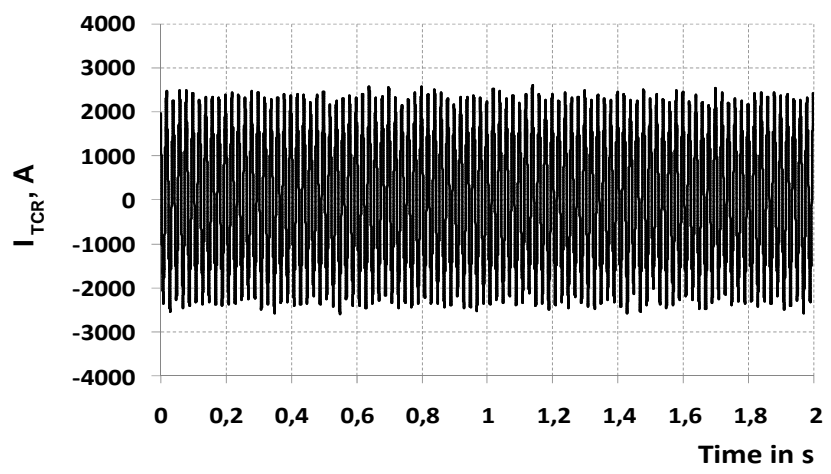

c)

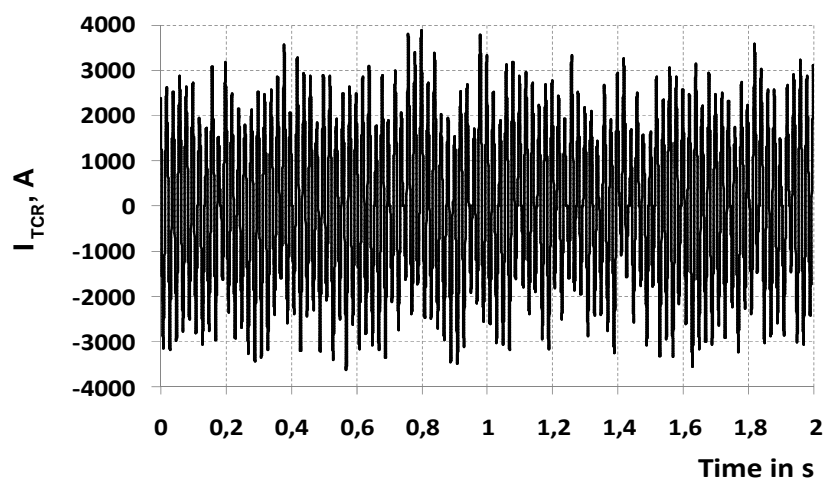

d)

Fig. 5. Simulated flicker level a), b) and instantaneous values of TCR current c), d) without a), c) and with b), d) operation of TCR reactive power control system. 


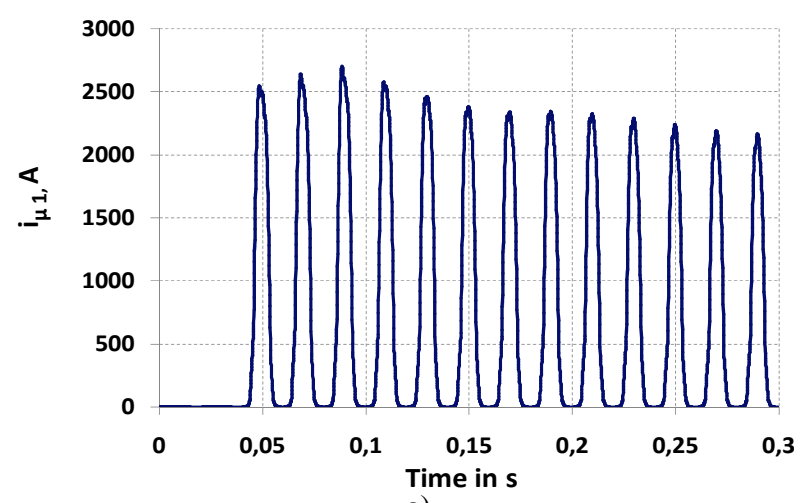

a)

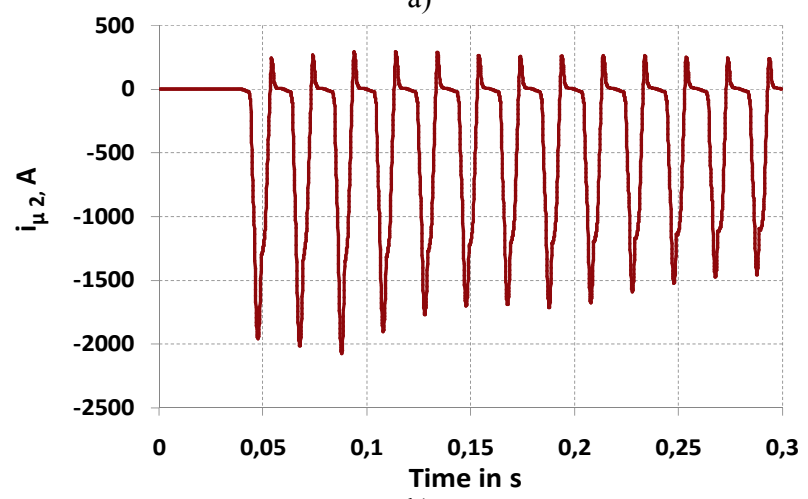

b)

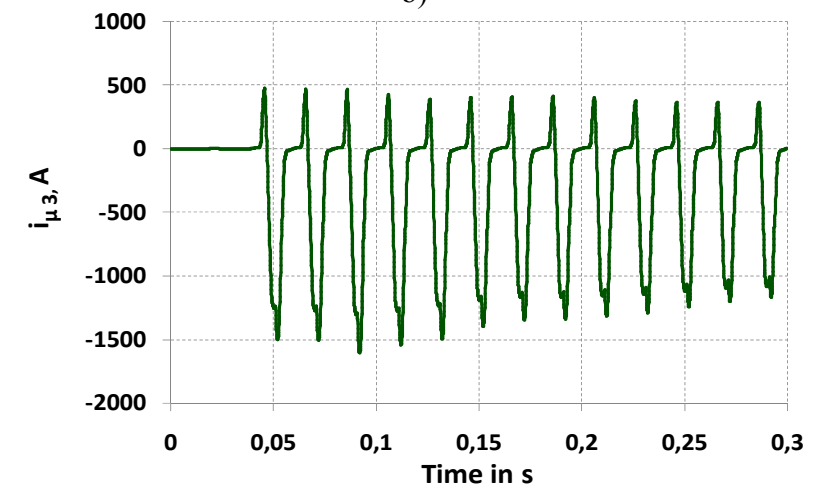

c)

Fig. 6 Simulated instantaneous values of transformer inrush currents in the phases: a) - R, b) - S and c) - T.

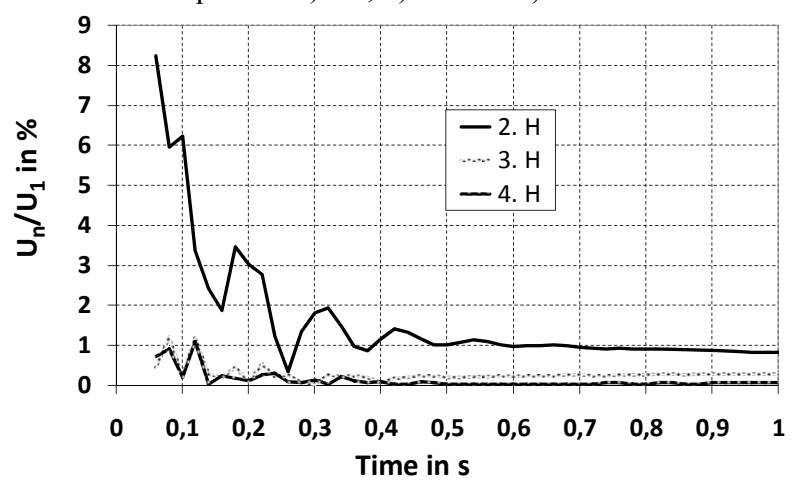

Fig. 7 Simulated harmonic voltages time courses during the inrush of furnace transformer.

\section{Summary}

The developed approach uses the computer model of complete steelmaking process and can be easily adapted for concrete melting profile and network operating state.
Statistic characteristics of expected values of power quality parameters can be easily estimated.

Reactive power compensation devices for several steel plants were designed according to the described approach. Some devices are already in operation.

\section{References}

[1] L. Kuchumov, A. Novitskiy, "Reactive Power Compensation of Non-Linear Loads on the Basis of the Analysis of Frequency Dependences of Electrical Supply Systems", in Proc. PCIM \& PQ Europe 1998, pp. 49-56.

[2] A. Novitskiy, Elektromagnetische Verträglichkeit und Blindleistungskompensation in Elektrostahlwerksnetzen (in German), Electromagnetic Compatibility and Reactive Power Compensation in Electric Steel Plants, Universitätsverlag, Ilmenau (2007), 248 p.

[3] S. Krämer, Beitrag zur Modellierung des elektrischen Betriebsverhaltens von Drehstromlichtbogenöfen ((in German), PhD-thesis, TU Ilmenau, 1997

[4] D. Stade, H. Schau, A. Novitskiy, I. Aprelkov "Method of the Mathematical Modelling of the Flicker Phenomena Caused by Ultra-High-Power AC Electric Arc Furnace", in Proc. PCIM \& PQ Europe 2002, pp. 51-56.

[5] D. Stade, H. Schau, A. Novitskiy, I. Konotop, "Flicker Analysis in the Transmission System", in Proc. PQ \& SR 2002, CD-ROM

[6] S. Prinz, Bewertung der Elektroenergiequalität in Netzen mit leistungsstarken Stromrichteranlagen unter Beachtung des Einflusses ihrer Regelung und Steuerung (in German) PhDthesis, TU Ilmenau, Ilmenau (2005)

[7] C. Plötner, Modellierung von Leistungstransformatoren unter Berücksichtigung der nichtlinearen Eigenschaften des Kerns sowie Betrachtungen zur Unterdrückung des Einschaltstromstoßes (in German), PhD-thesis, TU Ilmenau, Ilmenau (1998)

[8] IEC/TR 61000-3-7 Electromagnetic compatibility (EMC) Part 3-7: Limits - Assessment of emission limits for the connection of fluctuating installations to $\mathrm{MV}, \mathrm{HV}$ and $\mathrm{EHV}$ power systems. Edition 2.0 2008-02

[9] IEEE Guide - Adoption of IEC/TR 61000-3-7:2008, Electromagnetic compatibility (EMC) - Limits-Assessment of emission limits for the connection of fluctuating installations to MV, HV and EHV power systems. IEEE Std 1453.1 ${ }^{\mathrm{TM}}-2012$

[10] GB/T 12326-2008 电能质量电压波动和闪变 Power quality - Voltage fluctuation and flicker

[11] Yu Hu, Zhifei Chen, Zhe Chen, Yue Yuan. "A New Method for Analyzing the Influence of the Impact Load in Steel Plant on Grid", in Proc. DRPT 2011

[12] Arash Dehestani Kolagar, Arash Kiyoumarsi, Mohhamad Ataei and Rahmat Allah Hooshmand. "Reactive power compensation in a steel industrial plant with several operating electric arc furnaces utilizing open-loop controlled TCR/FC compensators", Euro. Trans. Electr. Power 2011; 21:824-838

[13] M. Panoiu, C. Panoiu, I. Şora, R. Rob. "Simulation of the Flicker Phenomenon based on Modeling the Electric Arc", WSEAS Trans. on Systems; Issue 10, Vol. 7, October 2008

[14] D. Stade, M.Malsch, H. Schau. „Upgrading the power quality with planning and operating of electric power systems supplying electric steel plants", in Proc. PQ \& SR 1999 [15] M.A.Golkar, S.Meschi. „MATLAB Modeling of Arc Furnace for Flicker Study“, in Proc. ICIT 2008

[16] IEC 61000-4-30. Electromagnetic compatibility (EMC) Part 4-30: Testing and measurement techniques - Power quality measurement methods. Edition 2.0 2008-10

[17] A. Novitzkij / H. Schau / D. Stade. "Analyse der Wechselwirkung zwischen nichtlinearen Belastungen der Elektrostahlwerksnetze (in German), Analysis of the interaction between non-linear loads of electrical networks of steel plants ", in Proc. $48^{\text {th }}$ IWK, 2003 